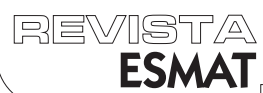

19

\section{CELERIDADE NO PODER JUDICIÁRIO E A EFICÁCIA}

CELERY IN THE JUDICIARY AND THE EFFECTIVENESS

Fernanda Cláudia Araújo da Silva

Mestre em Direito e doutoranda, pela Universidade de Lisboa. Professora da Faculdade de Direito da Universidade Federal do Ceará. E-mail:f.c.araujo@hotmail.com.

Josélia da Silveira Nogueira

Mestre em Direito e servidora do Tribunal de Justiça do Estado de Santa Catarina. E-mail: silveiranogueira@gmail.com.

\section{RESUMO}

objetivo do presente estudo é abordar os principais conceitos que envolvem as denominações: eficiência e eficácia, e correlacionar os termos com a busca pela celeridade no Poder Judiciário. Para alcançar os resultados, foi utilizado o meio bibliográfico de consulta com a pesquisa, de forma que se verificou que o Poder Judiciário brasileiro tem apresentado resultados que atendem a uma demanda relacionada a prazos e números, enquanto questões ligadas à qualidade na gestão do Judiciário são renegadas a segundo plano.

PALAVRAS-CHAVE:Eficiência. Eficácia. Poder Judiciário. Celeridade e Gestão.

\section{ABSTRACT}

The objective of the present study is to address the main concepts involving the denominations: efficiency and effectiveness and to correlate the terms with the search for speed in the Judiciary. To reach the results, the bibliographic means of consultation with the research was used, so that it was found that the Brazilian Judiciary has presented results that meet a demand related to deadlines and numbers, while issues related to the quality of judiciary management are reneged second plan.

KEYWORDS: Efficiency. Effectiveness. Judiciary. Speed and Management. 


\section{INTRODUÇÃO}

O Poder Judiciário brasileiro tem um papel estratégico na promoção da equidade social. Contudo, em virtude de sua complexidade, vem recebendo críticas da sociedade para que seus resultados se desenvolvam com mais dinamismo. Neste trabalho serão abordados temas com o objetivo de melhorar os serviços públicos judiciários, extirpando a precariedade anunciada diuturnamente pelos meios de comunicação.

De uma forma pragmática, são especificadas questões que envolvem o papel da liderança no setor público e sua importância nesse momento de crise pela qual passa o Judiciário.

Com a reforma decorrente da Emenda Constitucional n 19, de 1998, a questão da eficiência se tornou assunto corriqueiro já que inserida no rol de princípios administrativos. E mais que isso, passou a ser utilizada como sinônimo de eficácia, o que pressupõe evidente equívoco considerando o que dispõe a ciência da administração. Em 2004, com a Emenda Constitucional n ${ }^{\circ} 45$, incluiu-se no art. $5^{\circ}$ da Constituição Federal (BRASIL, 1988) o inciso LXXVIII, que trata da razoável duração do processo e da celeridade.

Esses acréscimos personificados em princípios administrativos constitucionais tratam de assunto relacionado diretamente à ciência da administração, a qual pode clarear os verdadeiros conceitos que envolvem a eficiência e a eficácia. Somando o comando constitucional e a semântica dessas duas palavras, é possível verificar algumas inconsistências que desafiam o Poder Judiciário, levando em conta que o jurisdicionado contemporâneo almeja que a solução de seus conflitos seja eficiente, mas também eficaz. Entretanto, com a economia fazendo cada vez mais parte do mundo do Direito, a exigência por eficácia no Poder Judiciário tomou força e gerou efeitos nem sempre desejados pelos jurisdicionados.

Ao lado da otimização, da concorrência e do atingimento de metas, a celeridade é uma das diretrizes da eficiência e está ligada à velocidade: os ritos devem ser reduzidos à metade e sofrer uma aceleração que acaba desencadeando deficiências específicas: otimizam-se recursos, e os servidores passam a ser apenas um número registrado em cada documento pré-elaborado pela própria instituição judiciária, deixando de ser um agente atuante, que pensa e é capaz de sugerir alterações importantes. Henry Mintzberg, Ph.D. pela MIT Sloan Schoolof Management, em entrevista exclusiva à Revista Administradores $n^{\circ} 5$, ensina que

[...] As pessoas têm as suas próprias necessidades e desejos, querem contribuir e se sentir parte da empresa. Logo, a maneira de tratá-las adequadamente é construindo o empreendimento como uma comunidade. Assim, os colaboradores vão se sentir realmente engajados ao invés de se sentirem ameaçados [...](MINTZBERG, 20 I I, p. I) 
Assim, o resultado é uma instituição desacreditada e despreparada para os desafios impostos na atualidade. Dessa forma, há de se ressaltar que a celeridade é perseguida pelo Poder Judiciário e está intimamente ligada aos conceitos de eficiência e eficácia. Eles trazem consigo premissas que influenciarão na vida de todos aqueles que esperam uma resposta objetiva e tempestiva do Judiciário.

A morosidade da justiça não será objeto deste estudo no que concerne às suas causas. Ao fim e ao cabo, pretende-se chamar a atenção para as falhas envolvendo principalmente o poder de gestão concedido aos magistrados e a eficácia e a eficiência decorrentes disso.

O fato é que, em busca de soluções para um Judiciário eivado de práticas obsoletas, o Conselho Nacional de Justiça (CNJ) passou a tratar os magistrados como gestores dos cartórios ou unidades judiciárias, encaminhando-Ihes ofícios com exigências e prazos a serem cumpridos. Números devem ser atendidos e, na figura de gestor das unidades judiciárias, o papel do magistrado foi ampliado sem prévio aviso. Entretanto, as competências do gestor não se coadunam com a de um juiz, demonstrando, no mínimo, falta de conhecimento por parte do Conselho Nacional de Justiça da estrutura judiciária interna vigente no País. Nesse sentido, questiona-se qual a possibilidade de as reformas impingidas ao Judiciário pelo Conselho Nacional de Justiça influenciarem na busca pela eficiência, enquanto os cidadãos pretendem também eficácia na solução de seus conflitos.

Para responder a esse questionamento, os princípios da eficiência, duração razoável do processo e celeridade serão abordados no sentido de servirem à sociedade quando junto vierem a eficácia dos procedimentos e as atitudes que se mostrem profícuas na busca pela celeridade, sem colocar em risco a qualidade do serviço público prestado pelo Poder Judiciário brasileiro.

Este estudo é apresentado em quatro partes, iniciando com a introdução na qual ficará clara a temática e sua importância. O referencial teórico será tratado no momento seguinte, em que conceitos sobre eficácia e eficiência, bem como teorias sobre planejamento estratégico serão apresentadas e algumas conclusões importantes sobre a figura do juiz-gestor. Os tipos de pesquisa, bem como a forma de elaboração do estudo, constam da metodologia. Na quarta etapa são apresentadas as considerações finais relacionadas ao tema estudado.

\section{REFERENCIAL TEÓRICO}

A Gestão do Judiciário está em foco, e em função disso muitas práticas estão se alterando, principalmente por determinação do Conselho Nacional de Justiça. A relação das mudanças com a busca por eficiência pode estar conduzindo a instituição judiciária a problemas que não são de fácil resolução. 


\section{I Eficiência: seu significado para o Poder Judiciário}

A eficiência, como princípio constitucional brasileiro, deve carregar consigo seu real sentido, que não se confunde com eficácia. Para atender ao princípio da razoável duração do processo, tanto que o Conselho Nacional de Justiça criou uma série de determinações que alteram a condução do Judiciário na busca pela eficiência.

No entanto, uma sentença tempestiva que não for bem justificada, ou não estiver intimamente relacionada com o caso constante na inicial, pode ser considerada eficaz? No cumprimento de sua missão, o Poder Judiciário deve ficar atento ao alcance da eficácia em seus procedimentos, sob pena de frustrar as partes, buscando somente a eficiência. Tomando por base ensinamentos da ciência da administração, Chiavenato dispõe que

Eficácia é uma medida normativa do alcance dos resultados, enquanto eficiência é uma medida normativa da utilização dos recursos nesse processo. (...) A eficiência é uma relação entre custos e benefícios. Assim, a eficiência está voltada para a melhor maneira pela qual as coisas devem ser feitas ou executadas (métodos), a fim de que os recursos sejam aplicados da forma mais racional possível (...). À medida que o administrador se preocupa em fazer corretamente as coisas, ele está se voltando para a eficiência (melhor utilização dos recursos disponíveis). Porém, quando ele utiliza estes instrumentos fornecidos por aqueles que executam para avaliar o alcance dos resultados, isto é, para verificar se as coisas bem feitas são as que realmente deveriam ser feitas, então ele está se voltando para a eficácia (alcance dos objetivos através dos recursos disponíveis). (CHIAVENATO, 1994, p. 70)

Eficácia diz com a inexistência de sentenças precipitadas, sem fundamentação completa, entre outros requisitos imprescindíveis. É preciso uma comunhão entre a adoção de procedimentos certos e o atingimento do que o público-alvo demanda; no caso, os jurisdicionados. Em entrevista dada à Revista Veja, o desembargador gaúcho Jorge Antônio Maurique afirmou que

Não adianta dar uma excelente decisão depois de muito tempo, porque a parte quer uma solução para a vida dela [...] sempre me preocupei com eficiência, com prazos rápidos e com um julgamento que fosse claro para que as pessoas entendessem o que nos levou àquela decisão. Então, procurei informação sobre o ISO 9001 com o departamento de planejamento do tribunal [...] todos nós recebemos treinamento sobre a necessidade de obter a certificação e começamos a fazer o que a norma exige, que é uma 
padronização de procedimentos. Quando recebo uma apelação em determinada área, há uma sequência a ser seguida [...] é como o checklist que os pilotos fazem antes da decolagem $[\ldots]$ isso acelera os resultados. (REVISTA VEJA, 20 I7, p. I)

Observando a prática do desembargador, verifica-se grande preocupação com o atendimento das demandas no tempo razoável, mas sem se esquecer da clareza que toda decisão judicial deve ter. Assim, avaliar as práticas judiciárias apenas levando em conta o conceito de eficiência é temerário no sentido de se deixar em segundo plano a qualidade dos serviços prestados.

Decisões judiciais céleres, mas não dotadas de eficácia, não compensam nem condizem com o que se espera do Judiciário. Implantar metas de produtividade é uma prática de gestão bastante interessante, desde que preservada a qualidade do serviço fornecido. Dada a importância que tem o tempo de duração do processo, e considerando a dinamicidade da sociedade, o inciso LXXVIII do art. $5^{\circ}$ da Constituição Federal (BRASIL, 1988), introduzido pela Emenda Constitucional $n^{\circ} 45$, de 2004, dispõe: "LXXVIII - a todos, no âmbito judicial e administrativo, são assegurados a razoável duração do processo e os meios que garantam a celeridade de sua tramitação".

No entanto, a reclamação dos jurisdicionados, e principalmente a dos operadores do Direito, é a de que, em nome de uma celeridade, muito tempo se despende. Parece contraditório, mas não é. Mintzberg (20 I I , p. I) defendeu: "[...] eu não sou nem um pouco fã da cultura corporativa de "mensuração". Penso que esta seja exagerada, com foco excessivo sobre [...] a gestão por objetivos, os sistemas de controle nas organizações $[\ldots . .$. ".

Assim, é válida a menção a um processo envolvendo a queda de teto de um dormitório de apartamento, ocorrida em 2016, e a construtora está sendo cobrada a ressarcir os danos. Num despacho saneador, é determinada perícia do local, em 2018. Evidente que as condições já se transformaram completamente: para que o imóvel voltasse a ser utilizado foi colocado teto de PVC.

Em 2019, o perito ainda não foi designado. E quando o for, já é previsível a sua resposta: não há o que ser periciado, pois o local já possui outro teto, de outra qualidade etc. E o custo da perícia deverá ser repartido pelas partes. Esse é o típico exemplo de análise rápida do caso, que gera resposta judicial errada, a qual atrasará mais o andamento do processo e ainda trará um custo extra para o demandante, custo este entendido por ele como inócuo, pois não irá colaborar com o caso, até porque já consta nos autos laudo particular de todos os apartamentos do prédio que tiveram problemas e laudo da Caixa Econômica Federal. Com o tempo, a realidade do local se transformou, e essa questão passou in albis, gerando prejuízo principalmente ao demandante.

Embasando esse exemplo, cita-se Correa (2014, p. I0I), para quem "eficiência somente não basta. Embora possa ser satisfeito o princípio da razoável duração do processo isso não significa que se produziu uma decisão eficaz, justa e adequada que resolve o problema, pois "uma justiça célere não é necessariamente uma justiça melhor" 
(CORREA, 2014, p. I0I).

A demanda impingida pelo Conselho Nacional de Justiça para que os juízes acumulem atividades diversas do jurisdicere transforma o magistrado em gestor. Se a questão se limitasse aos cargos de direção seria natural a nova concepção.

Entretanto, no que tange à gestão dos cartórios, é questionável a expansão das atividades do magistrado. Acoimado de artesanal o trabalho do juiz por ouvir as partes, proferir despachos e sentenças, considerando caso a caso, importante é ressaltar que essas são tarefas intrínsecas ao ato de decidir, independentemente do atendimento de produtividade e metas do Conselho Nacional de Justiça.

Na opinião de Paulo Eduardo Alves da Silva (2010, p. 35), o "gerenciamento de processos" pode ser compreendido com o planejamento da condução de demandas judiciais em direção à resolução mais adequada do conflito, com o menor dispêndio de tempo e custos. Depende de uma postura ativa do juiz no controle do andamento dos feitos e organização da unidade judiciária.

No entanto, não procede ao entendimento de que quanto mais o juiz-gestor exercer uma liderança eficiente, mais tempo terá para a atividade jurisdicional. Somente quem não conhece a realidade das unidades judiciárias brasileiras pode declarar válido conceder ao magistrado a condição de gestor. Inicialmente, existe um problema de estrutura que impossibilita uma gestão eficiente.

Para quem desconhece, ressalte-se que o juiz não divide seu espaço de trabalho com os servidores que dão andamento no processo dentro do cartório. A equipe do juiz está em sala conjugada com a do magistrado, e essa é composta por pessoas que, agora sim, podem ser gerenciadas por ele, já que ligadas estruturalmente a ele. Para Colzani,

Constata-se que as Varas Judiciais são quase que autônomas em seu gerenciamento e como tal elas deveriam ser administradas. Entretanto, a maior parte dos Juízes e Escrivães não sabem e não foram orientados e ensinados para gerenciar gabinete/cartório, no caso de juiz, e o de gerenciar cartório quando Escrivão Judicial. E por outro lado a instituição não possui um setor ou departamento que seja responsável pela organização e gerenciamento das pessoas responsáveis pelo cartório. Cada qual adota uma forma de trabalhar sem planejamento ou metas. Ou se existem é por iniciativa pessoal do Juiz ou do Escrivão. (COLZANI, 2017, p. 3)

A busca por agilidade é tanta que encontramos no site do Tribunal de Justiça de Santa Catarina a seguinte informação:

é com satisfação que anunciamos que a partir de hoje, dia 8-42019, o Sistema de Assistência Judiciária Gratuita (AJG-PJSC ) está disponível para todo o Poder Judiciária de Santa Catarina [...] e propiciará ainda mais agilidade, segurança e transparência 
[...]A prestação jurisdicional terá seu andamento acelerado [...]. $(2018$, p. I)

Para o desembargador do Tribunal de Justiça de Rondônia, Marcos Alaor Diniz Grangeia, o Poder Judiciário passa por uma crise de gestão, e observa que,

Aos olhos de muitos que se dedicam à análise dos problemas da Justiça, está patente que a crise instalada no Poder Judiciário deriva da falta de agilidade e possui um viés gerencial com consequências na economia do país, no desprestígio social do Poder e na segurança pública. O sistema judiciário de solução de conflitos necessita ser equacionado para contribuir para a melhoria da velocidade confiabilidade do Poder Judiciário. Nessa perspectiva, a atividade desenvolvida por magistrados e servidores de cartório, na administração da serventia, ganha relevo e transcende a própria sentença, pois esta passou a ser apenas um capítulo da jornada jurisdicional. (GRANGEIA, 201 I, p. 28)

Daí a importância do presente debate. $\bigcirc$ foco é repensar os procedimentos para alcançar mais agilidade na prestação jurisdicional. E isso envolve questões que passam pela gestão do Judiciário, invariavelmente.

Um caso que serve como exemplo tramitou no Tribunal de Justiça do Rio Grande do Sul. Um processo envolvendo o caso judicial da Boate Kiss, relativo a um incêndio ocorrido em 27. I .20 I 3, de conhecimento por todos, dada a repercussão pelo número de vítimas, ou seja, duzentas e quarenta e duas pessoas, sem contar as seiscentas e oitenta que se feriram.

Foi intitulado por Birnfeld (2017, p. I) como a "mais notória tartaruga jurídica gaúcha". Trata-se de um processo com mais de vinte mil páginas, formando mais de setenta volumes e vinte e sete apensos.

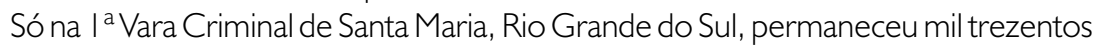
e sessenta e dois dias. Chegou à ${ }^{a}{ }^{a}$ Câmara Criminal do Tribunal de Justiça do Rio Grande do Sul (TJRS), no gabinete do desembargador Manoel Martinez Lucas, em $1^{\circ}$ de novembro de 2016, e em 22 de novembro os autos foram remetidos ao Ministério Público, retornando, com parecer, em uma semana. E desde 30 de novembro de 2016 manteve-se em "conclusão para julgamento ao relator".

O Judiciário está desaparelhado de conceitos e práticas de planejamento do principal serviço que presta à sociedade. Dar razoável duração a um processo como o da Boate Kiss é bem diferente de acompanhar os trâmites dos demais processos, reclama um método diferenciado. Então, mostra-se uma necessidade peculiar que, como se vê, é tratada num rol comum.

Processos da envergadura da Boate Kiss devem ser trabalhados de forma diversa, pela quantidade de pessoas envolvidas e pela repercussão que geram. Não se trata de 
dar mais celeridade porque está na mídia, mas sim de ter um olhar diferente sobre o processo como um todo, sob pena de causar indignação dos envolvidos no caso. É necessário pensar na existência de núcleos de trabalho para casos como esse. Como relata o professor José Isaac Pilati, no livro Audiência Pública na Justiça do Trabalho (20 I 5), que adapta o modelo romano à complexidade da realidade atual, "desafiando a lógica do processo civil tradicional".

A expectativa que as pessoas têm é a de que o Judiciário apontará os culpados e os punirá, o problema é "quando". E o tempo faz toda a diferença, sempre e principalmente quando se trata de vidas humanas.

A falta de adaptação dos procedimentos processuais usuais à realidade do processo da Boate Kiss é algo cristalino, não tem como tratar um processo desses como mais um processo. "É preciso adaptar o que já existe a novos propósitos", afirma Peter Burke (2009, p. l).

E contrariando todas essas informações negativas, o então presidente do Tribunal de Justiça do Rio Grande do Sul (TJRS), desembargador Luiz Felipe Difini (20।7), em entrevista, disse que seu primeiro ano de gestão foi positivo:

o Poder Judiciário conseguiu em 2016, apesar do cenário de crise profunda, manter os seus indicadores positivos, pois julgamos mais processos do que entraram [...] a conquista do Selo Ouro conferido pelo Conselho Nacional de Justiça, a conclusão de 156 mil processos a mais que os ajuizados e a evolução do processo eletrônico.

Parece contraditória a avaliação de Difini, considerando os grandes números envolvendo o caso da Boate Kiss. E o que dizer aos pais das vítimas que assistem a tudo perplexos e desacreditados do Poder Judiciário. Diante de várias informações negativas que comprovam o caos do sistema judiciário, a condecoração ainda tem lugar e deixa os jurisdicionados revoltados.

\subsection{A Gestão do Judiciário pelo Magistrado}

Colzani esclarece que

[...] as Varas Judiciais são quase que autônomas em seu gerenciamento e como tal elas deveriam ser administradas. Entretanto, a maior parte dos Juízes e Escrivães não sabem e não foram orientados e ensinados para gerenciar gabinete/cartório, no caso de juiz, e o de gerenciar cartório quando Escrivão Judicial. E por outro lado a instituição não possui um setor ou departamento que seja responsável pela organização e gerenciamento das pessoas responsáveis pelo cartório. Cada qual adota uma forma de trabalhar sem 
planejamento ou metas. Ou se existem é por iniciativa pessoal do Juiz ou do Escrivão. (COLZANI, 2017, p. 3)

Assim, com os olhos voltados para a rapidez dos procedimentos, torna-se imprescindível a implantação de um planejamento, para que os resultados exigidos pelo Conselho Nacional de Justiça possam ser atendidos a contento.

Mas é necessário planejar, aplicando conhecimento específico principalmente no que concerne aos servidores, que são aqueles que farão os números se modificarem. A pergunta é: Quem está mais atento e tem mais ferramentas para aplicar uma estratégia de funcionamento que reduza a morosidade judicial? Para Mintzberg (20 I I), "[...] não é preciso um grande gênio para se sentar ali e disparar os números para as pessoas, dizendo "isso é problema seu". Essa é uma dispensa total do processo natural de estratégia, e as pessoas precisam começar a colocar as mãos na massa até que saibam o que está ocorrendo, para então poder atacar e resolver os problemas.

Coloca-se como imprescindível saber lidar com pessoas, o que não é uma meta simples de ser alcançada. Feito isso, é possível inicial o processo de planejamento. $E$ dentro de todas essas habilidades, o magistrado deve preocupar-se com sua atribuição principal. Para esclarecer melhor, Darós (2009) conceitua o planejamento estratégico da seguinte forma: É a arte de administrar, a partir de princípios teóricos, procedimentos metodológicos e técnicas de grupo, perseguindo metas que levem a uma mudança na cultura da organização. Pressupõe decisões para o futuro, mas, especialmente, perquire, constantemente, qual o futuro das decisões que se vai tomar.

Ocorre que o juiz fica impossibilitado de dar abrangência às demandas que um cartório requer, já que a estrutura que envolve o magistrado é diversa daquela do cartório. Por sua vez, o escrivão ou chefe de cartório tem as ferramentas necessárias para implementar o planejamento correto.

Na lição de Schulze (apud MAXIMIANO):

Planejamento estratégico é o processo de elaborar a estratégia - a relação pretendida da organização com seu ambiente. $\bigcirc$ processo de planejamento estratégico compreende a tomada de decisões sobre o padrão de comportamento (ou cursos de ação) que a organização pretende seguir: produtos e serviços que pretende oferecer e mercados e clientes que pretende atingir. [...] Um processo sistemático de planejamento estratégico é uma sequência de análises e decisões que compreende as seguintes etapas principais: (I) Análise da situação estratégica presente da organização. (Onde estamos? Como chegamos aqui?) (2) Análise do ambiente - ou análise externa. (Quais são as ameaças e as oportunidades do ambiente presente e futuro?) (3) Análise interna. (Quais são os nossos pontos fortes e fracos?) (4) Definição do plano estratégico. (Para onde devemos ir?) $\bigcirc$ que devemos fazer para chegar até lá?). (SCHULZE, 20 I I, p. I) 
Assim, o ambiente dinâmico que caracteriza o cartório apresenta todos os indicativos para ser objeto de planejamento com vista a um bom funcionamento da unidade judiciária cartorial, o que irá refletir no trabalho do magistrado. E a tomada de decisões deve partir de alguém que esteja dentro desse contexto.

O juiz da vara ou unidade judiciária tem seu gabinete, com sala para seus assessores em separado, ou seja, não tem contato direto com o cartório. A dinâmica do cartório é totalmente diferente da do gabinete.

A eficiência para a rapidez nos procedimentos processuais deve ser equacionada no cartório, e não no gabinete, que é um ambiente mais reduzido e com menos procedimentos burocráticos. Importante a contribuição dada por Mintzberg quando menciona que

Planejar significa que você pode se sentar e criar uma fórmula. Porém, estratégias não saem assim, como milagre. Elas são aprendidas quando se tem um alvo, quando as pessoas precisam resolver problemas. Penso que gestão é gestão. Não é uma profissão nem uma ciência, mas uma prática, e eu não acredito que ela tenha se transformado fundamentalmente. A modificação que eu aceitaria não é sobre as funções, mas em relação às pressões e características do gerenciamento. (201 I, p. I).

Só o cotidiano do cartório imprime no líder o conhecimento suficiente daquilo que demanda um planejamento efetivo. E esse líder deve estar presente, observando tudo que ocorre e gerenciando cada novo problema que surge. Muitas propostas de melhoria nas práticas de um cartório precisam ser revistas, pois se trata de terreno de grande rotatividade, tanto no que concerne às atividades quanto às pessoas.

Sousa (20|4) observa que o tempo de tramitação de processos judiciais é reiteradamente apontado como um dos maiores obstáculos da Justiça brasileira. Contudo, o ritmo do tempo de tramitação quem dita são os Cartórios Judiciais, que têm recebido pouca atenção nos debates sobre a melhoria dos serviços judiciários. Para o professor Aurélio L. Andrade (2017), "a estrutura influencia comportamentos que geram eventos. Não se muda um padrão de comportamento sem mudar a estrutura”.

Assim, almejar que o magistrado gerencie sua unidade jurisdicional, seu cartório, significa, primeiramente, mudar a atual estrutura onde funciona a unidade jurisdicional, trazê-la para mais perto do juiz. A dúvida que fica é se existe interesse nessa mudança estrutural do atual formato que vige no Judiciário brasileiro.

Uma questão leva à outra: é sistêmico e assim deve ser visto. Não existe fórmula mágica, e a ciência da administração está aí para provar isso. Mintzberg afirma que

[...] a gestão é muito afetada pelas constantes interrupções, as várias pequenas tarefas do dia, todas essas coisas que a tornam caótica, a orientação para a ação [...] a gestão está acontecendo 
em três planos: informação, ação e pessoas. Assim, os gestores processam informações, se comunicam, controlam ao mesmo tempo em que lidam com pessoas, constroem networks do lado de fora e lideram dentro da organização. Já os gerentes se envolvem com a ação, pois eles administram projetos, apagam incêndios, negociam contratos. (201 I, p. I)

Essa diferenciação feita pelo autor é extremamente importante, apesar de parecer, inicialmente, dizer respeito à iniciativa privada. A gestão pelos magistrados é completamente válida quando se fala de Presidência da Instituição ou Diretoria do Fórum. Nesses casos, eles são, efetivamente, os gestores. $\bigcirc$ que se quer tratar no presente estudo é da "gerência" de que trata Mintzberg. Ela diz respeito ao juiz que está no controle de uma vara judicial, composta por cartório e gabinete.

Daí a importância da escolha desse líder específico. Almejar celeridade é nobre, mas há muito trabalho por trás desse objetivo, e isso demanda alguém com habilidades específicas. Mintzberg esclarece a esse respeito:

[...] Eu não creio que a liderança não é importante. Para mim, liderança e gestão não podem ser separadas, pois são intrinsecamente ligadas uma a outra. Acredito que os gestores que não lideram são chatos e desanimadores. Por outro lado, os líderes que não gerenciam não sabem o que está acontecendo. (20। I, p. I)

É disso que se trata quando se fala que o magistrado não tem como administrar a unidade jurisdicional: falta logística, falta conhecimento, sem contar que não prestaram concurso com esse objetivo.

A iniciativa do Conselho Nacional de Justiça falhou por esquecer que liderança e gestão andam juntas. Se o magistrado não é o líder imediato, não se envolve com o que ocorre diariamente dentro da unidade, sua capacidade de gestão fica prejudicada, como reforça Mintzberg:

[...] a liderança e a gestão têm que estar contidas nas mesmas pessoas. Você pode distinguir em um sentido que liderança é em relação a energizar, motivar as pessoas e tudo mais, mas eu não acho que você pode separar a liderança da gestão. Bons líderes estão no cotidiano da empresa, em contato com os clientes, o mercado e seus colaboradores. Eles sabem o que está acontecendo, não estão microgerenciando nem se metendo nos assuntos dos seus gestores subordinados. Eles simplesmente estão na operação, porque você não desenvolve estratégias simplesmente sentando no ar; você precisa estar no chão, intervindo no dia a dia [...] (20 I I, p. I) 
Sociologicamente, essa ode à eficiência relaciona-se ao movimento neoliberal. Julio Cesar Marcellino Jr. (2008, p. 10) ressalta que "num ambiente onde prevalecem a velocidade e o culto canônico à cibercultura, não haveria tempo para atividades de engajamento, estudo e reflexão. $\bigcirc$ que importa são estatísticas quantitativas, atingimento de metas, a celeridade, a produtividade".

\section{METODOLOGIA}

Objetivando apresentar as relações existentes entre a busca pela eficiência e o contraponto a respeito da eleição do magistrado para gerir a unidade judiciária, foi utilizada a pesquisa bibliográfica, importante no presente caso, porque, segundo Lakatos (20 I0, p. 166), esse tipo de pesquisa "não é mera repetição do que já foi dito ou escrito sobre certo assunto, mas propicia o exame de um tema sob novo enfoque ou abordagem, chegando a conclusões inovadoras".

Os números que se quer do Judiciário proporcionam uma corrida descontrolada por eficiência, e o planejamento necessário para alcançar resultados positivos acaba gerando estresse nos gestores magistrados.

As teorias da ciência da administração que demonstram como funciona essa engrenagem incrementam o estudo presente. Optou-se pelo método descritivo, observando fatos e observando teorias para chegar a conclusões sobre as melhores práticas em prol da celeridade. Além disso, "características de determinada população ou fenômeno, estabelecendo correlações entre as variáveis estudadas" foram expostas. (Vergara, 2005).

O objetivo não é minimizar a importância da celeridade. Paulo Cezar Alves Sodre (20 I 4, p. I 3) fez uma colocação que ilustra isso, quando menciona: "não se ignora que a celeridade processual é um instrumento importantíssimo para a consolidação do acesso à justiça, não sendo, portanto, a celeridade processual e o acesso à justiça objetivos excludentes. Muito ao contrário, eles se complementam".

A pesquisa é qualitativa com uma análise de conteúdo, o qual proporciona suporte para responder às seguintes indagações: a) A eficiência, por si só, já é suficiente para dirimir os problemas por que passa o Judiciário brasileiro? b) Incluir nas atribuições dos magistrados a responsabilidade por gerir os cartórios judiciais é viável diante do atual modelo vigente? Para compreender bem a problemática sobre a morosidade processual, e a busca desenfreada por agilidade no Judiciário, também serviu a experiência prática da autora no cartório da I ${ }^{a}$ Vara Criminal de Araranguá, estado de Santa Catarina.

\section{CONSIDERAÇÕES FINAIS}

O que se verifica é que temos um órgão público que imprime demandas ao Poder Judiciário, por via da pessoa do magistrado. A ele é imposto o cumprimento de metas e o gerenciamento de uma unidade jurisdicional que já tem um chefe de cartório ou 
escrivão à frente. Baseando-se em conceitos de planejamento estratégico advindos de uma séria de administradores de renome internacional, é possível verificar que alcançar o êxito nessa empreitada será tarefa das menos corriqueiras.

Em nome da celeridade, cobram-se de forma errada resultados que atingirão frontalmente a qualidade do serviço público prestado pelo Judiciário. E quando o juiz está verificando números para informar o Conselho Nacional de Justiça deixa de trabalhar em sua atividade principal, que é dizer o direito, missão que o motivou a prestar o concurso. Se deixa de fazê-lo, demonstra ao jurisdicionado que suas funções, agora ampliadas, não permitem a dedicação exclusiva de produção intelectual jurídica, o que a sociedade não concordaria se fosse consultada. É bem sabido que o que se quer é que o juiz julgue logo, decida os conflitos em andamento, mas essa vontade não se reflete no que o Conselho Nacional de Justiça pretende para o Poder Judiciário.

O economista chileno Carlos Matus desenvolve a ideia de que: [...] o plano tradicional tem como base uma teoria do controle de um sujeito sobre um sistema e afirma explicitamente que a realização do planejamento exige certo grau de controle Essa concepção de planejamento é, evidentemente, autoritária, determinista e, em alguma medida, positivista. [...] (1996, pp. 47 e 48). Este trabalho teve como objetivo demonstrar que a eficiência do Poder Judiciário está atrelada à eficácia, e que a adoção de estratégias de resultado na prestação de serviços para uma melhor gestão dos cartórios judiciais demanda a escolha da liderança correta. $\bigcirc$ presente estudo apresentou conclusões de administradores renomados a respeito da efetividade do planejamento estratégico e da importância na escolha de um líder nesse processo de prestação dos serviços judiciais. Ainda como objetivo, procurou-se trazer exemplos relacionados ao Judiciário e que ilustram bem a aplicação de técnicas nos cartórios judiciais que não atendem ao que o cidadão brasileiro necessita. Assim, alcançaram-se os objetivos propostos, o que torna o processo demorado nos dias atuais pode ser intensificado se alterarmos os objetivos principais do magistrado no Judiciário.

A ausência de gestão procedimental da engrenagem judiciária faz com que os processos tenham tramitação mais lenta porque se ampliaram demais as tarefas do juiz. Decorrente do trabalho elaborado, é possível sugerir que a liderança imposta ao magistrado seja transferida ao chefe de cartório ou a existência de um departamento em cada instituição judiciária voltado ao controle da qualidade dos processos e procedimentos, que promova treinamentos periódicos e mudanças na cultura das pessoas que prestam serviço público.

\section{REFERÊNCIAS}

ANDRADE, Aurélio L. O curso do pensamento sistêmico. Print Editora. São Paulo. 2014.

ANDRADE, Aurélio L. Pensamento Sistêmico na Prática. In: Workshop sobre pesquisa aplicada, promovido pela Universidade Federal de Santa Catarina em 25. I I.20 I 7. 
BIRNFELD, Marco A. Onde estão as ideias. Espaço Vital - Jornal do Comércio (http://jcrs.uol.com.br/_conteudo/20 I7/02/colunas/espaco_vital/545467-grandetartarugajuridica-em-acao.html). Acesso em: II fev. 2017 BRASIL, Constituição Federal. Brasília: Senado Federal, 1988. Disponível em: http://www.planalto.gov.br/ccivil_03/constituicao/constituicao.htm.

BURKE, Peter. Reciclando ideias. Folha de São Paulo, Caderno Mais, 25 maio 2009. Disponível em: https://wwwl.folha.uol.com.br/fsp/mais/fs24052009|2.htm - acesso em: I 5 abr.20I9.

CHIAVENATO, Idalberto. Recursos humanos na Empresa: pessoas, organizações e sistemas. 3. ed. São Paulo: Atlas, 1994. p. 67-76.

COLZANI, Antônio. A importância da gestão de processos em cartórios da justiça de $I^{\circ}$ grau de Santa Catarina. Disponível em: < http://tjsc25.tjsc.jus.br/academia /arquivos/Antonio_Colzani.pdf> Acesso em: 21 ago. 2017.

CORREA, Priscilla Pereira Costa. Direito e Desenvolvimento: aspectos relevantes do Judiciário Brasileiro sob a ótica econômica. Brasilia: Conselho da Justiça Federal, Centro de Estudos Judiciários, 2014.

DARÓS, Vilson. (2009). Planejamento Estratégico do TRF da $4^{a}$ Região. Caderno de Administração da Justiça: Planejamento Estratégico.

GRANGEIA, Marcos Alaor Diniz. Administração judiciária - gestão cartorária. $\left.\right|^{a}$ Edição. Brasília, ENFAM. 20I I. I56p.

Modelagem Organizacional, Gestão Administrativa e de Procedimentos Judiciais de Cartório Cível. Porto Velho: FGV Direito. 2007.

JUNIOR, Julio Cesar Marcellino. O direito de acesso à justiça e a análise econômica da litigância: a maximização do acesso na busca pela efetividade. Universidade Federal de Santa Catarina. Tese submetida ao Curso de Doutorado do Programa de Pósgraduação em Direito da Universidade Federal de Santa Catarina como requisito para a obtenção do título de Doutor em Direito. Orientador: Prof. Dr. Horácio Wanderlei Rodrigues. Florianópolis. 2014.

LAKATOS, E. M. Fundamentos de metodologia científica. 7. ed. São Paulo:Atlas, 2010. 
PILATI, José Isaac. Audiência pública na justiça do trabalho. 2 ed. Rio de Janeiro: Lumen Juris. 2015. MATUS, Carlos e HUERTAS, Franco (1996). O método PES. entrevista com Matus I ed. São Paulo: Fundap. p. 47 e 48.

RABIN, Claudio Goldberg. O Judiciário se acostumou a não ser cobrado. Revista Veja, fev. 20 17. Disponível em: < http://veja.abril.com.br/brasil/o-judiciario-se-acostumoua-naoser-cobrado/> Acesso em: 3 fev. 2017.

SODRÉ, Paulo Cezar Alves. A administração do poder judiciário e o acesso à justiça no Brasil: as alterações introduzidas pela emenda constitucional n 45/2004. Florianópolis. 20 | 4. Curso de Mestrado em Direito, Estado e Sociedade. Dissertação apresentada ao Curso de Pós-graduação Strictu Sensu em Direito, Programa de Mestrado, da Universidade Federal de Santa Catarina. Disponível em < https://repositorio.ufsc.br/xmlui/bitstream/handle/I 23456789// 03243/274 I 65.pdf?se quence $=\mid$ \&isAllowed $=y>$. Acesso em: 6 abr. 2018 .

SAGRERA, Renato. Radio Universidade, fev. 2017. Presidente Difini faz balanço do primeiro ano de gestão à frente do TJRS. Disponível em: Acesso em: I 5 abr. 2019.

SCHULZE, Clenio Jair. $\bigcirc$ planejamento estratégico e o juiz administrador. Revista Jus Navigandi, Teresina, ano I6, n. 2840, I I abr. 20 I I.

SILVA, Paulo Eduardo Alves da Silva. Gerenciamento de processos judiciais. Saraiva, 2010.

SILVA, Paulo Eduardo Alves da; NOGUEIA, Mauro Oddo. In: OLIVEIRA, Saulo Barbará de. (Org. e Coautor). Instrumentos de gestão pública. São Paulo: Saraiva, 20 I 5. p. |87-216.

SODRÉ, Paulo Cezar Alves. A administração do poder judiciário e o acesso à justiça no Brasil: as alterações introduzidas pela emenda constitucional $n^{\circ} 45 / 2004$. Florianópolis. 20 14. Curso de Mestrado em Direito, Estado e Sociedade. Dissertação apresentada ao Curso de Pós-graduação Strictu Sensu em Direito, Programa de Mestrado, da Universidade Federal de Santa Catarina. Disponível em < https://repositorio.ufsc.br/xmlui/bitstream/handle/I 23456789// 03243/274 I 65.pdf?se quence $=\mid$ \&isAllowed $=y>$. Acesso em: 6 abr. 2018 .

SOUSA, Roberto Rodrigues de. Gestão de pessoas e de processos no ambiente cartorário. 24 jul. 2017 . Disponível e m: < http://www.tjdft.jus.br/institucional/imprensa/artigos/20 I 4/gestao-de-pessoas-e-deprocessosno-ambiente-cartorario-roberto-rodrigues-de-sousa > Acesso em: 15 abr. 2019. 
VERGARA, Sylvia Constant. Projetos e relatórios de pesquisa em administração. 3. Ed. São Paulo: Atlas, 2000.

WEIBLEN, Bruno Weiblen e FREITAS, Eber, Henry Mintzberg critica fórmulas prontas do planejamento estratégico. Revista Administradores, set. 201 I .

Recebido em: 16/10/2020

Aprovado em: | 8/0 | /2020 